\title{
Pedagogical Opportunities for Formation of Intercultural Tolerance Competence in English Language Classes
}

\author{
Dilnoza Kurbanova Arslanovna \\ ${ }^{I}$ Research Scholar, Teacher at Jizzakh Polytechnic Institute, Uzbekistan \\ Email:dilnoza_kurbonova8386@mail.ru
}

\begin{abstract}
In this article the problems and factors of upbringing of tolerance at schools are demonstrated. Pedagogical opportunities of formation tolerance on younger generation and also the importance of knowledge in understanding the intercultural communication in education process are clarified in it.

Keywords: tolerance, intolerance, multinational students, tolerance education, factors of tolerance, social experiences.
\end{abstract}

\section{INTRODUCTION}

Today in our country there is a strong guarantee of the stability of the atmosphere of interethnic harmony and solidarity. Currently, there are 137 cultural centers in the country. Our country connects East and West. Due to its location at the crossroads of the Great Silk Road, our people are embodied in the cultural and spiritual heritage of different nations and peoples, and the tolerance, hospitality and generosity of our nation are ingrained in our blood.

At the same time, to instill a sense of tolerance in the minds of the younger

generation, as well as the emergence of such qualities as kindness and loyalty, has reached universal value. The foundation of our future that we are building with education system plays an important role in the promotion of tolerance in the minds of young people. The reason is that human beings are scientifically and systematically absorbed the social experiences and values accumulated in the educational institutions.

In particular, "the Declaration of Principles of Tolerance" states that education is one of the most effective means of preventing intolerance and should help strengthen tolerance.

Also Education policies and programs should help to improve understanding, solidarity and tolerance among individuals, ethnic, social, cultural and religious nations.[1]

\section{MAIN PART}

Foreign language lessons play a special role in shaping the concept of intercultural tolerance on students. Because in foreign language classes, the student not only can have a lot of knowledge about that culture, but also learns to be kind to them, to treat them with respect, as well as to be sympathetic. It should be noted that over the years, not enough attention has been paid to inculcating the concept of intercultural tolerance at English lessons. The formation of the student's outlook in life within the framework of moral norms has a special social and pedagogical significance. The development of intercultural tolerance in the education of students should become the main goal of every educator, not only in foreign language classes, but in all subjects. This is because most of the misunderstandings between people in society are the result of their insufficient knowledge of intercultural tolerance.

Today, in the process of teaching English in general secondary schools, the necessary pedagogical forces for engaging on students in all-round communications are gradually being used.

But, unfortunately, the results of our observations show that the education of intercultural tolerance in English classes is not carried out according to the basis of the logic required by society. This reduces students' opportunities to develop their language learning competencies. This is because if foreign language classes are conducted in harmony with the national and other national cultures, their interest in language learning will increase and their competencies in language learning will be further 
developed. Unfortunately, even the teachers themselves are in some cases unstable and impatient with the students.

What is required of educators is to provide students with basic experiences in building intercultural tolerance. It is advisable that this action should be carried out mainly in the educational process. This is a little easier in English classes. When a teacher teaches a foreign language to students, he does not hold the lessons without paying attention to the culture and customs of that people. With this movement, he creates a sense of intercultural tolerance on students. Nevertheless, there is a strong need for scientific and methodological recommendations for the formation of tolerance in the educational process.

\section{Methods and Materials}

One of the main elements of the formation of intercultural tolerance in English classes is the system of values and evaluation which are formed on the basis of certain knowledge. The more objective and deep the knowledge, the stronger will be the values and evaluation. The reason is that there is a lot of misunderstandings and loss of affection among uneducated and people without good knowledge. From this point of view, it should be noted that the words of our great ancestor Abu Raykhan Beruniy, "People treat hostile to the things that they do not have knowledge about it," have a deep meaning[2].

Russian scholars have also put forward a number of views on fostering tolerance in the education system. According to G.N. Serikov, the following factors are required to create tolerance in the environment of the education system[3]:

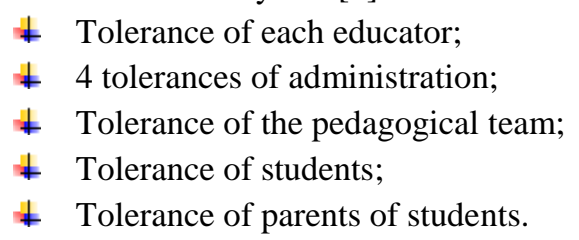

Only as a result of the interaction of these factors, the functioning of a rigid system was observed on students.

According to I. V.Mirotvorskaya, the interdisciplinary model of forming tolerant consciousness and behavior requires the integration of all pedagogical methods and techniques of forming a culture of tolerance, regardless of its content and direction. Each educational institution should be able to organize laboratories and develop methods of forming a culture of tolerance, based on its capabilities[4].

To the point of T.Kh.Akbarov, U.B.Orunbaev, cultivating tolerance on students in the classroom includes:

* 1.Explain students that everything in the world is different.

* 2.Explain that nations are different in race, religion, and way of life.

* 3.Explain students that nations differ from each other.

\# 4.To be tolerant and patient with the uniqueness of people.

\$ 5. To teach citizens to live in mutual peace.

\# 6.Educate young people to increase responsibility, with a sense of responsibility.

* 7. Fostering calmness, tolerance, patience, endurance on younger generation[5].

According to Uzbek scientists G. Tillaeva, "Tolerance is one of the main factors in the formation of personality, it is a key factor in ensuring interethnic harmony, the attitude to society in the conflict situations that occur during the exchange of civilizations, ensuring its stability". Because as a result of the development of intercultural tolerance on pupils and students, their attitude to social life will be changed. Their ability to create different projects, to participate in different types of conversations, debates will be expanded.

As U. Kudratova says: "In general, historical-genetic analysis helps to pay special attention to the following aspects of tolerance. First, tolerance is a factor that ensures the development of society, and secondly, tolerance is the social order of the education system[6].

Accordingly, tolerance as a social order in the education system is manifested in the following areas:

Tolerance is instilled on learners as a social value.

\# Inter-ethnic tolerance is formed on students. 
\# Interpersonal tolerance is appeared on students.

In conclusion, we cannot express tolerance as an interethnic and social value without forming interpersonal tolerance. Because a person's being soft-spoken and patience on the basis of a tolerant relationship with that around him will be the basis for his future success.

According to Gulbahor Akramova, young people with the concept of tolerance develop the ability to receive different information and assimilate it objectively[7]. To do this, a working environment must be created among students. Teachers should support the work environment in the classroom. In the education of tolerance it is recommended to use pedagogical measures, determining the level of individuality, originality, propensity to master the concepts of tolerance, the level of habituation to creative thinking.

In this regard, it is necessary to perform the following tasks to cultivate intercultural tolerance on students in English classes:

\# Explain to students in English classes from primary school that people should be different and live in a good relationship with them.

* Explain to students that each nation has valuable characteristics by conveying materials about different folk cultures, so it should be treated with care, their culture should be treated with respect.

\# To teach people not to consider the culture and way of life of their own people as superior to the culture of other nations.

* Achieve the development of language skills in English classes by teaching students intercultural tolerance.

\# Teach students to work in groups in English classes.

\section{Result}

The analysis of our research shows that it is relevant to form the concept of intercultural tolerance among students of our country. This is due to the fact that people of different nationalities have lived together in our country for many years. The formation of the concept of intercultural tolerance is an important means of ensuring harmony, stability and development in society. This means that we need to pay special attention to the formation of intercultural tolerance on students at secondary schools.

Intercultural tolerance is a complex phenomenon that covers all spheres of individual and social life, having many aspects, components, many manifestations and directions.

The upbringing of tolerance at school should be first and foremost relevant to the content of the learning process. What teachers do at the beginning of each lesson is to provide the students with their first experience of tolerance. This should be done mainly in the educational process. This activity can be quite effective in English classes, in the elementary grades, given that one teacher carries out the learning process itself. It is worth noting that there is a lack of didactic developments on schoolchildren. At the same time, there is a strong need for scientific and methodological recommendations on the formation of tolerance in the educational process. Formation of tolerance in the learner's mind requires extensive use of both individual and group work. In the process, a group of students is formed as a team. At the same time, each student feels that they have a supportive family around him.

As a result of the close interaction with others in the environment, the student's personality develops. This is because communication between members of society is an important source of development. It can also serve as a guiding factor for the student's future development.

So, creating intercultural tolerance on students can be done in all classes of schools, but it is much more effective, especially in foreign language classes. Additional materials on the formation of a sense of intercultural tolerance should be included at school foreign language curriculum. At the same time, foreign language lessons should be enriched with videos and films that reflect the culture of the peoples of the world, presentation materials, scenes that express traditions and values, and texts from real life.

Dialogue is also an important form of interpersonal tolerance and it is an important way to build relationships, interpersonal interaction and communication with other people belonging to other cultures. $\mathrm{T}$ this type of tolerance that all aspects of the tolerance problem (both in terms of its learning and teaching and development) are clearly reflected.

Additionally, a separate organized culture day can be very effective way for forming intercultural tolerance in English language classes, which will create a travel environment for the culture 
of the peoples of the world. This lesson should include materials related to other cultures, pictures that reflect other cultures, clothing, information about customs and values, excerpts from national songs, or scenes that reflect that culture. It should be noted that all of these materials should be done connected with foreign language lessons.

So along with individual work in the formation of intercultural tolerance on students, the widespread use of group activities contributes to the formation of students' ideas as a team.

\section{CONCLUSION}

This, the formation of intercultural tolerance on students is of great importance. This is especially effective in English classes. By instilling intercultural tolerance on students, we teach people of different nationalities, who have lived in our country for hundreds of years, to respect each other's culture, as well as Uzbek culture, in peace and harmony. This requires enriching and equipping the teaching process with new ideas in foreign language classes.

\section{REFERENCES}

[1] Declaration of Principles of Tolerance // UNESCO International Normative Documents.T .: Adolat, 2004.

[2] G.N. Serikov. "Factors of Pedagogical Influence on the quality of selflearning students" Bulletin of the South Ural State University. Ser.Education. Educational Sciences. 2017, vol. 9, no. 3, pp. 22-36

[3] Abu Raykhan Beruni. Translations. T. Heritage, 1991

[4] Mirotovskaya I.V. The formation of tolerance in senior students of secondary schools in the process of legal education: Diss. ... Ph.D. - Cheboksary, 2004. - P.82-84

[5] T.X.Akbarov, U.B.Orunboev. KGPI Batken State University, Kyrgyzstan "Problems of formation of tolerance in the educational process". Ziyonet.library.uz

[6] Kudratova U "Factors of formation of interpersonal tolerance in the educational process and the activities of teachers in it" .ziyonetlibrary.uz

[7] Akromova G.R. Fostering tolerance in the student is a requirement of the time. // "Education and development newspaper, August 8, 2012, Fikr.uz. 